Artigos

Volume 10 - $2020 \mid$ n. 9

\title{
Plano Nacional de Educação 2014 e o Plano Estadual de Educação 2016: implicações no financiamento da educação especial no estado de São Paulo
}

\author{
Marcia Maurilio Souza \\ Vanessa Dias Bueno de Castro \\ Rosângela Gavioli Prieto \\ Universidade de São Paulo (USP), São Paulo/SP - Brasil
}

\section{Resumo}

O movimento mundial em prol da inclusão do alunado elegível ao atendimento pela educação especial, acentuado na década de 1990, culminou, em 2008, com a publicação de texto orientador da política de educação especial que prioriza as matrículas desses alunos em classes comuns. Tal orientação foi reforçada no Plano Nacional de Educação (2014) e adotada pelo Plano Estadual de Educação de São Paulo (2016), mas esses documentos preveem o repasse de verbas públicas às instituições sem fins lucrativos de educação especial por meio de parcerias. Tivemos por objetivo apresentar e analisar as transferências de recursos financeiros feitas pela Secretaria de Educação do Estado de São Paulo a essas instituições, utilizando fontes documentais (legislação, dados de matrículas e de recursos financeiros). Constatamos que as parcerias com a referida secretaria de educação são constantes e visam contribuir para a subsistência das instituições que oferecem ensino especializado, porém consideramos que as políticas de educação especial adotadas pela secretaria contrariam a perspectiva inclusiva, posto incentivar a manutenção e possível aumento do atendimento substitutivo.

Palavras-chave: Financiamento. Educação Especial. Parcerias. Estado de São Paulo.

\section{The National Education Plan 2014 and the State Education Plan 2016: implications for the financing of special education in the state of São Paulo}

\begin{abstract}
The worldwide movement in favor of the inclusion of students eligible for special education assistance, accentuated in the 1990s, culminated in 2008 with the publication of a text guiding the special education policy that prioritizes the enrollment of these students in common classes. Such guidance was reinforced in the National Education Plan (2014) and adopted by the State Education Plan of São Paulo (2016), but these documents provide for the transfer of public funds to non-profit special education institutions through partnerships. We aimed to present and analyze the transfers of financial resources made by São Paulo State Department of Education to these institutions, using documentary sources (legislation, enrollment data and financial resources). We note that the partnerships with the aforementioned Education Department are constant and aim to contribute to the subsistence of institutions that offer specialized education, however, we consider that the special education policies adopted by the department contradict the inclusive perspective, since it encourages maintenance and possible increase substitute care.
\end{abstract}

Keywords: Financing. Special Education. Partnerships. State of São Paulo. 
Plano Nacional de Educação 2014 e o Plano Estadual de Educação 2016

\section{Introdução}

Historicamente, o atendimento educacional oferecido ao alunado elegível ao atendimento pela educação especial - hoje, pessoas com deficiência, transtornos globais do desenvolvimento (TGD) e altas habilidades/superdotação - foi delegado, no Brasil, ao setor privado, ou seja, às instituições sem fins lucrativos (comunitárias, confessionais e filantrópicas) (JANNUZZI, 1992; MAZZOTTA, 2003; BUENO, 1993; FERREIRA, 1993; KASSAR, 1998).

A partir da década de 1990, acompanhando o movimento mundial em prol da inclusão social e escolar das pessoas com deficiência, em nosso país também começaram a ser implementadas ações nesse sentido, que culminaram com a publicação do documento Política Nacional de Educação Especial na Perspectiva da Educação Inclusiva (BRASIL, 2008). Com base em suas diretrizes, os sistemas de ensino passaram a se reorganizar no sentido de oferecer ao alunado, elegível ao atendimento pela educação especial, condições de matrícula, permanência e aprendizagem nas classes comuns com os apoios necessários: sala de recursos multifuncionais, atendimento educacional especializado (AEE), intérprete de língua de sinais, guia-intérprete, profissionais de apoio para atividades de vida diária, entre outros recursos pedagógicos que promovam a acessibilidade do aluno à escola e ao currículo (SOUZA, 2017; 2018).

O que se tem observado, desde as primeiras ações governamentais no sentido de implementar a educação inclusiva, é um tensionamento político entre os grupos que apoiam a inclusão escolar e os que têm a intenção de manter o atendimento pelas instituições especializadas sem fins lucrativos. O que resulta desses embates é a manutenção dessas instituições para o oferecimento de educação especial substitutiva ${ }^{1}$ e/ou a oferta de AEE, nesse caso organizado em Centros de Atendimento Educacional Especializado (Caee), subvencionados técnica e financeiramente pelos entes federados (estaduais e municipais) por meio de parcerias ${ }^{2}$, decorrente do alto grau de organização dessas instituições, que têm influências políticas junto aos órgãos legislativos federais (REBELO, 2015; MELO; SILVA, 2018).

$\mathrm{Na}$ legislação nacional, desde a Constituição da República Federativa do Brasil CF/1988 - (BRASIL, 1988), passando pela Lei de Diretrizes e Bases da Educação Nacional -LDB/1996 (BRASIL, 1996) e pelo Plano Nacional de Educação - PNE/2014 (BRASIL, 2014a), quando é garantido o direito à matrícula do referido alunado elegível ao atendimento pela educação especial, mantém-se a prerrogativa "preferencialmente na rede regular de ensino", a qual possibilita que as matrículas também sejam efetivadas em instituições que ofereçam a educação especial substitutiva.

1 Diz respeito à educação especial oferecida em classes e escolas especializadas exclusivas, públicas e privadas, em substituição à matrícula do estudante elegível ao atendimento pela educação especial na classe comum, em que ele tem direito ao atendimento educacional especializado (AEE) no contraturno.

2 Para este artigo adotamos o termo "parceria" em consonância com Di Pietro (2017, p. 26), que o utiliza "[...] para designar todas as formas de sociedade que, sem formar uma nova pessoa jurídica, são organizadas entre os setores público e privado, para a consecução de fins de interesse público. Nela existe a colaboração entre o poder público e a iniciativa privada nos âmbitos social e econômico, para a satisfação de interesses públicos, ainda que, do lado particular, se objetive o lucro. Todavia, a natureza econômica da atividade não é essencial para caracterizar a parceria, como também não o é a ideia de lucro, já que a parceria pode dar-se com entidades privadas sem fins lucrativos que atuam essencialmente na área social e não econômica". 
Plano Nacional de Educação 2014 e o Plano Estadual de Educação 2016

Reiteramos aqui o que definimos como educação especial substitutiva oferecida nas instituições parceiras e também em algumas redes públicas de ensino, em classes e escolas especiais. Quando o aluno frequenta tais classes e escolas, apesar de ele estar incluído em uma escola regular, ou seja, reconhecida pelo sistema de ensino, entendemos que ele está em uma escola exclusiva, porque é tirado desse aluno seu direito de frequentar a classe comum, com os apoios necessários para sua permanência e aprendizagem, assim como de ter o atendimento do AEE no contraturno, como preconiza a educação especial na perspectiva da educação inclusiva (BRASIL, 2008). No caso em que o aluno frequente a classe comum e tenha a necessidade do atendimento no AEE no contraturno, esse pode ser oferecido na sala de recursos multifuncionais da própria escola em que o aluno estuda, em uma escola próxima ou, ainda, em um Caee público ou privado.

Em relação à pressão política para perdurar a destinação de recursos públicos para instituições sem fins lucrativos, Melo e Silva (2018, p. 4) indicam que a Federação Nacional das Apaes $^{3}$ (Fenapaes), durante a tramitação do PNE/2014, "[...] defendeu as Apaes como espaço legítimo de escola especial para crianças e jovens com deficiência intelectual e/ou associada a outras deficiências".

A Meta 4 do PNE/2014 traz, em sua primeira estratégia, a reafirmação do apoio financeiro às instituições sem fins lucrativos pelo repasse do Fundo de Manutenção e Desenvolvimento da Educação Básica e de Valorização dos Profissionais da Educação (Fundeb), e reitera as parcerias com essas instituições em mais quatro estratégias $(4.4,4.17$, 4.18 e 4.19) (BRASIL, 2014a). De modo específico, no estado de São Paulo, o Plano Estadual de Educação 2016 - PEE-SP/2016 - reproduz o caput da Meta 4 e a estratégia 4.1 do documento nacional, que dizem respeito ao repasse do Fundeb, e mais duas estratégias que reiteram as parcerias com as instituições sem fins lucrativos, quais sejam, a 4.6 que visa a: "Garantir o Atendimento Educacional Especializado, Classes Regidas por Professor Especializado - CRPE, escolas ou serviços educacionais especializados [...]" e a 4.9, que visa a "[...] ampliar a oferta de formação continuada e a produção de material didático, assim como os serviços de acessibilidade necessários à aprendizagem [...]", ambas em relação aos "[...] estudantes com deficiência, transtornos globais do desenvolvimento e altas habilidades ou superdotação, matriculados na rede pública de ensino" (SÃO PAULO, 2016a).

A Secretaria de Educação do Estado de São Paulo (SEE-SP) mantém parcerias com esse tipo de instituição para oferecimento de educação especial substitutiva ao ensino comum, utilizando-se de legislação específica para celebração de termos de colaboração conforme a Resolução SE 59/2016 (SÃO PAULO, 2016b), que "[...] dispõe sobre o processo de credenciamento de organizações da sociedade civil sem fins lucrativos [...]" (SÃO PAULO, 2016b) e o Decreto n. ${ }^{\circ}$ 62.294/2016 (SÃO PAULO, 2016c, grifo nosso), o qual:

Autoriza a Secretaria da Educação a representar o Estado na celebração de termos de colaboração, com organizações da sociedade civil, sem fins lucrativos, atuantes em educação especial, selecionadas por chamamento público ou previamente credenciadas pela Pasta, com o objetivo de promover o atendimento a educandos com graves deficiências que não puderem ser beneficiados pela inclusão em classes comuns de ensino regular, e dá providências correlatas.

3 Associação de Pais e Amigos dos Excepcionais. 
Plano Nacional de Educação 2014 e o Plano Estadual de Educação 2016

Devemos destacar que quando os Termos de colaboração citam como objetivo "promover o atendimento a educandos com graves deficiências", está se referindo a:

\begin{abstract}
[...] educandos com deficiência intelectual, deficiência múltipla associada a deficiência intelectual, que necessitem de apoio permanente-pervasivo, ou para atendimento de educandos com Transtorno do Espectro Autista ou deficiência múltipla associada ao Transtorno do Espectro Autista, que necessitem de apoio substancial ou muito substancial, correspondentes aos níveis de gravidade 2 e 3 , de acordo com o Manual de Diagnóstico e Estatística dos Transtornos Mentais $5^{\mathrm{a}}$ Edição (DSM-5) [...] (SÃO PAULO, 2016c).
\end{abstract}

Podemos afirmar que a SEE-SP possui uma perspectiva de inclusão parcial e não total, pois no documento está presente "[...] a ideia de que a diversidade de características implica a existência e manutenção de um contínuo de serviços e de uma diversidade de opções" (MENDES, 2006, p. 396), quando ele indica que algumas categorias de alunos com deficiência e transtornos do espectro autista são inelegíveis para o atendimento nas classes comuns.

O referido Decreto apresenta a minuta-padrão de Termos de Colaboração e os inc. II e III do artigo $2 .^{\circ}$ estabelecem como devem ser aplicados os recursos financeiros: "[...] para pagamento da remuneração dos profissionais encarregados da execução do objeto do ajuste, bem como para atender a outras despesas previstas no artigo $46^{4}$ da Lei Federal n. ${ }^{\circ}$ 13.019/2014, alterada pela Lei Federal n. ${ }^{\circ} 13.204 / 2015$, desde que incluídas no respectivo plano de trabalho". O inc. III indica:

O cálculo da quantia a ser transferida dar-se-á mediante a multiplicação do número de alunos cadastrados e matriculados na entidade parceira, pelo valor fixado pela Secretaria da Educação, a ser estimado no mês de junho do ano anterior ao do exercício a que se destina o correspondente repasse, adotando-se como parâmetro o valor anual por aluno, na modalidade educação especial, previsto para o Fundo de Manutenção e Desenvolvimento da Educação Básica e de Valorização dos Profissionais da Educação - FUNDEB (SÃO PAULO, 2016c, grifos nossos).

Isso posto, neste artigo é explorado analiticamente o financiamento da educação especial do estado de São Paulo por meio das parceiras entre SEE-SP e instituições sem fins lucrativos que oferecem educação especial substitutiva. Para tanto, temos como balizadores a Meta 4 do PNE-2014 e do PEE-SP 2016, com ênfase nas estratégias que indicam apoio técnico e financeiro às instituições sem fins lucrativos e a legislação estadual relativa às parcerias.

Desse modo, temos por objetivo identificar os montantes estimados para repasse do Fundeb com base nas matrículas nessas instituições, pelos serviços prestados com o oferecimento de educação especial substitutiva, assim como os valores pagos efetivamente pela SEE-SP para essas instituições, no período de 2014 a 2017, recursos esses garantidos pela legislação federal e estadual e, assim, apresentar considerações sobre o que podemos denominar de implicações desse apoio a essas instituições que mantêm parcerias com a SEE-SP.

4 São elas: II - diárias referentes a deslocamento, hospedagem e alimentação nos casos em que a execução do objeto da parceria assim o exija; III - custos indiretos necessários à execução do objeto, seja qual for a proporção em relação ao valor total da parceria (BRASIL, 2015a). 
Plano Nacional de Educação 2014 e o Plano Estadual de Educação 2016

\section{Metodologia}

Para alcançarmos nossos objetivos, desenvolvemos uma pesquisa qualitativa, de análise de documentos que, conforme Sá-Silva, Almeida e Guindani (2009), faz uso de fontes primárias e possibilita ampliar o entendimento dos objetos cuja compreensão requer contextualização histórica e social.

Assim, como documentos de pesquisa, foram selecionados a legislação nacional e estadual paulista sobre financiamento, particularmente desde a vigência do Fundeb; dados dos Microdados do Censo Escolar da Educação Básica do Instituto Nacional de Estudos e Pesquisas Educacionais Anísio Teixeira (Inep) obtidos por meio do portal do Laboratório de Dados Educacionais da Universidade Federal do Paraná (UFPR), para reunir dados referentes às matrículas nas instituições especializadas parceiras da SEE-SP e secretarias municipais; do endereço eletrônico do FNDE extraímos os documentos: Instituições conveniadas e alunos considerados na distribuição dos recursos do Fundeb - 2018 e as Portarias Interministeriais que estabelecem os parâmetros operacionais do Fundeb para os exercícios anuais; e no portal da Secretaria da Fazenda do Estado de São Paulo (SF-SP), coletamos nos balanços consolidados ${ }^{5}$ os valores relativos aos pagamentos efetuados para as instituições especializadas relativos às parcerias com a SEE-SP.

A escolha dos períodos analisados (2014-2017 e 2014-2018) deu-se em função, primeiramente, da publicação do PNE-2014 e, posteriormente, dos dados mais atualizados disponíveis no momento da pesquisa. Desse modo, os dados dos Microdados do Censo da Educação Básica e os Balanços Consolidados da Secretaria da Fazenda do Estado de São Paulo estavam disponíveis até 2017 e os valores do Fundeb até 2018.

Os dados quantitativos referentes às matrículas em instituições especializadas com atuação exclusiva em educação especial conveniadas com a SEE-SP e aos repasses de verbas foram organizados em planilhas do Microsoft Excel na formatação de tabela, a fim de facilitar a sua interpretação e análise.

\section{Resultados e Discussões}

Das fontes documentais, extraímos as informações referentes às instituições sem fins lucrativos que oferecem educação especializada substitutiva, com parceria junto à SEE-SP, como já mencionado.

Para termos uma visão geral das matrículas do alunado matriculado em classes exclusivas nas instituições especializadas que mantêm parcerias com secretarias de educação no estado de São Paulo, apresentamos na Tabela 1 a série histórica de 2014 a 2017, com o número de matrículas na educação especial (educação básica) por etapas e modalidades de ensino. Segundo o Censo da Educação Básica do Inep as classes exclusivas são aquelas com "[...] matrículas de alunos com algum tipo de deficiência, transtorno global do desenvolvimento e altas habilidades/superdotação em Escolas Exclusivamente Especializadas e/ou em Classes Exclusivas de Ensino Regular e/ou EJA" (BRASIL, 2017b).

5 Resultado da agregação das demonstrações contábeis, neste caso, dos órgãos estaduais, pela SF-SP. Disponível em: <https://bit.ly/2GrrZ6Z>. Acesso em: 15 abr. 2019. 
Plano Nacional de Educação 2014 e o Plano Estadual de Educação 2016

Vale ressaltar que, apesar do presente estudo ter como foco as instituições parceiras com a SEE-SP, as matrículas apresentadas na Tabela 1 estão formalizadas em instituições que também são parceiras de secretarias de educação municipais. Não há como desagregar esses dados nos instrumentos utilizados para esta pesquisa, ainda que tenhamos recorrido ao portal do "Laboratório de Dados Educacionais" da UFPR para levantamento dos dados relativos às matrículas da educação especial em classes exclusivas nas "instituições conveniadas", estas englobam as instituições parceiras com os órgãos municipais de educação e com a SEE-SP.

Tabela 1 - Estado de São Paulo - Evolução das matrículas na educação especial (educação básica) em classes exclusivas ${ }^{1}$ (classes e escolas especiais) privadas parceiras de secretarias de educação (2014-2017)

\begin{tabular}{|c|c|c|c|c|c|}
\hline \multicolumn{2}{|c|}{ Etapa de ensino } & 2014 & 2015 & 2016 & 2017 \\
\hline \multirow{3}{*}{$\begin{array}{l}\text { Educação } \\
\text { Infantil }\end{array}$} & Creche & 467 & 414 & 441 & 452 \\
\hline & Pré-Escola & 605 & 605 & 555 & 554 \\
\hline & Total & 1072 & 1019 & 996 & 1006 \\
\hline \multirow{3}{*}{$\begin{array}{l}\text { Ensino } \\
\text { Fundamental }\end{array}$} & Anos Iniciais & 28.609 & 26.238 & 25.465 & 26.456 \\
\hline & Anos Finais & 1.538 & 1.561 & 1.421 & 596 \\
\hline & Total & 30.147 & 27.799 & 26.886 & 27.052 \\
\hline \multirow{4}{*}{ Ensino Médio } & Propedêutico & 277 & 239 & 161 & 81 \\
\hline & Normal Magistério & 0 & 0 & 0 & 0 \\
\hline & Técnico Integrado & 0 & 0 & 0 & 0 \\
\hline & Total & 277 & 239 & 161 & 81 \\
\hline \multirow{4}{*}{$\begin{array}{c}\text { Educação de } \\
\text { Jovens e } \\
\text { Adultos }\end{array}$} & $\begin{array}{c}\text { Ensino } \\
\text { Fundamental }\end{array}$ & 3.855 & 3.098 & 2.642 & 685 \\
\hline & Ensino Médio & 160 & 89 & 93 & 78 \\
\hline & Profissionalizante & 0 & 0 & 0 & 0 \\
\hline & Total & 4.015 & 3.187 & 2.735 & 763 \\
\hline \multicolumn{2}{|c|}{ Total Geral } & 35.511 & 32.244 & 30.778 & 28.902 \\
\hline
\end{tabular}

Fonte: Organizada pelas autoras a partir de informações colhidas no portal do Laboratório de Dados Educacionais da UFPR. Nota 1 - Inclui matrículas de alunos com algum tipo de deficiência, transtorno global do desenvolvimento e altas

habilidades/superdotação em Escolas Exclusivamente Especializadas e/ou em Classes Exclusivas de Ensino Regular e/ou EJA.

Verifica-se que em todos os anos apresentados há uma concentração das matrículas no ensino fundamental - com uma porcentagem crescente no período, correspondendo a $84,9 \%$ (2014), 86,2\% (2015), 87,4\% (2016) e 93,6\% (2017). Destas, a maior parte, em torno de $94 \%$ a $97 \%$ no período, está nos anos iniciais do ensino fundamental. Além disso, observase que há uma redução considerável das matrículas do ensino médio quando comparadas às registradas no ensino fundamental, as primeiras representam em 2014 e $2015-0,9 \%$, em $2016-0,6 \%$ e em 2017 - 0,3\% das matrículas do ensino fundamental, indicando dificuldade de acesso desse público a essa etapa da educação básica e a quase ausência de oferecimento dessa etapa de ensino em classes exclusivas. Há um número significativo de matrículas na Educação de Jovens e Adultos (EJA), sendo que as matrículas na EJA Ensino Fundamental correspondem a 96\% (2014), 97\% (2015), 83\% (2016) e 90\% (2017) do total das matrículas na EJA e algumas poucas matrículas são da EJA Ensino Médio. No entanto, 
houve uma redução expressiva dessas matrículas no período, de 4.015 em 2014 para 763 em 2017 - o equivalente a $81 \%$, reforçando a avaliação sobre o baixo acesso a níveis mais elevados de ensino. Cabe também destacar que essa realidade do estado de São Paulo corresponde à nacional, apresentada em trabalhos como o de Meletti e Ribeiro (2014).

Ainda é possível constatar na Tabela 1 que houve uma diminuição no número de matrículas em cada etapa e modalidade de ensino durante o período analisado nas classes e escolas especiais privadas das instituições parceiras. No total, as matrículas passaram de 35.511 em 2014 para 28.902 em 2017, ou seja, sofreram redução de aproximadamente 18,6\%. De maneira específica, a Educação Infantil passou de 1.072 para 1.006 matrículas, correspondente a uma diminuição de cerca de 6,1\%, apesar de ter ocorrido uma ligeira elevação entre 2016 e 2017; o Ensino Fundamental, que sofreu a maior redução em número absoluto - justificado por ser a etapa que mais concentra matrículas -, passou de 30.147 matrículas em 2014 para 27.052 em 2017, ou seja, redução de $10,3 \%$ no período; no Ensino Médio ocorreu redução de 277 matrículas em 2014 para 81 matrículas em 2017 correspondente a 70,8\%; a Educação Profissional nessas instituições parceiras não registrou matrículas no período analisado, por essa razão não foi incluída na tabela.

Essa tendência de diminuição de matrículas em classes e escolas especiais no estado de São Paulo acompanha os índices de matrículas nacionais nessa mesma modalidade de ensino, apontando para os resultados dos programas e ações dos sistemas de ensino dos entes federados para implementar a educação especial na perspectiva inclusiva (SOUZA; PAGAIME; ROSA, 2018).

Dando continuidade à análise, na Tabela 2 está registrada a série de valores do Fundeb aluno/ano para a educação especial de 2014 a 2018 para o estado de São Paulo, assim como os números de matrículas na educação especial nas classes comuns (públicas - estaduais e municipais e privadas), no AEE (redes municipais e estadual) e nas instituições parceiras com as secretarias municipais e estadual paulista, foco deste trabalho, para o período de 20142018. Essas matrículas nas instituições parceiras não estão desagregadas entre as secretarias municipais e a SEE-SP. Como nos demonstrativos do FNDE são apresentados somente o valor estimado total de todo o montante a ser repassado, estimamos os valores apresentados multiplicando o número de matrículas (nas classes comuns, no AEE e nas instituições) pelo valor aluno/ano para a educação especial.

Tabela 2 - Estado de São Paulo - Valores do Fundeb aluno/ano na educação especial e valores estimados de repasse do Fundeb para as matrículas da educação especial nas classes comuns, AEE e instituições especializadas parceiras (valores nominais em $\mathbf{R} \$$ )

\begin{tabular}{|c|c|c|c|c|c|c|c|c|c|c|}
\hline \multirow[b]{2}{*}{ Ano } & \multirow{2}{*}{$\begin{array}{c}\text { Valor } \\
\text { aluno/ano } \\
\text { Fundeb } \\
\text { Educação } \\
\text { Especial }\end{array}$} & \multirow{2}{*}{$\begin{array}{l}\text { Matrículas na } \\
\text { educação } \\
\text { especial (rede } \\
\text { pública - } \\
\text { estadual e } \\
\text { municipal) }\end{array}$} & \multirow{2}{*}{\multicolumn{2}{|c|}{$\begin{array}{c}\text { Matrículas no } \\
\text { Atendimento } \\
\text { Educacional } \\
\text { Especializado } \\
\text { (AEE) }\end{array}$}} & \multirow{2}{*}{$\begin{array}{c}\text { Matrículas em } \\
\text { instituições } \\
\text { parceiras de } \\
\text { educação } \\
\text { especial para } \\
\text { repasse } \\
\text { Fundeb } \\
\end{array}$} & \multicolumn{4}{|c|}{ Valores estimados para repasse do Fundeb } & \multirow{2}{*}{$\begin{array}{c}\text { Percentual } \\
\text { relativo às } \\
\text { matrículas } \\
\text { nas } \\
\text { instituições } \\
\text { parceiras }\end{array}$} \\
\hline & & & & & & $\begin{array}{l}\text { Matrículas nas } \\
\text { redes públicas }\end{array}$ & $\begin{array}{c}\text { Matrículas no } \\
\text { AEE }\end{array}$ & $\begin{array}{c}\text { Matrículas nas } \\
\text { Instituições } \\
\text { Parceiras }\end{array}$ & Total & \\
\hline 2014 & $3.640,67$ & $104.799,0$ & $\rrbracket$ & $38.610,0$ & $\sqrt{15.511}$ & $381.538 .575,33$ & $140.566 .268,70$ & $129.283 .832,37$ & $651.388 .676,40$ & $20 \%$ \\
\hline 2015 & $4.068,60$ & $102.079,0$ & $\mathbf{t}$ & $40.266,0$ & 32.244 & $415.318 .619,40$ & $163.826 .247,60$ & $131.187 .938,40$ & $710.332 .805,40$ & $18 \%$ \\
\hline 2016 & $4.273,85$ & $94.186,0$ & $\downarrow$ & $37.072,0$ & 30.778 & $402.536 .836,10$ & $158.440 .167,20$ & $131.540 .555,30$ & $692.517 .558,60$ & $19 \%$ \\
\hline 2017 & $4.304,32$ & $98.519,0$ & $\boldsymbol{t}$ & $44.639,0$ & 28.902 & $424.057 .302,08$ & $192.140 .540,48$ & $124.403 .456,64$ & $740.601 .299,20$ & $17 \%$ \\
\hline 2018 & $4.505,32$ & $104.821,0$ & $\mathbf{t}$ & $48.753,0$ & 28.837 & $472.252 .147,72$ & $219.647 .865,96$ & $129.919 .912,84$ & $821.819 .926,52$ & $16 \%$ \\
\hline
\end{tabular}

Fonte: Organizado pelas autoras a partir de dados coletados nas Portarias Interministeriais do FNDE/MEC (BRASIL, 2014b; 2015b; 2015c; 2016a; 2016b; 2017b); Portal do Laboratório de Dados Educacionais da UFPR.

Nota 1 - Valor estimado calculado pelas autoras. 
Plano Nacional de Educação 2014 e o Plano Estadual de Educação 2016

Analisando a Tabela 2, podemos fazer as seguintes considerações em relação às matrículas da educação especial: nas classes comuns partimos de 104.799 matrículas em 2014, sendo que houve no período variações de altas e quedas no quantitativo, as quedas foram dominantes entre 2014-2015 (2,6\%) e 2015-2016 (7,7\%), e os aumentos aconteceram entre 2016-2017 (4,6\%) e 2017-2018 (6,4\%). Comparando os dados de 2014 e 2018, verificase aumento de 21 matrículas - eram 104.799 em 2014 e passaram a ser 104.821 em 2018.

Em relação às matrículas no $A E E$, alunos que frequentam a classe comum e no contraturno o AEE, em números absolutos, houve crescimento entre os anos 2014-2015 (4,3\%), redução entre 2015-2016 (8\%), um crescimento sensível entre 2016-2017 $(20,4 \%)$ e um aumento de $9,2 \%$ entre $2017-2018$. De modo geral, no período analisado foi registrado aumento de aproximadamente $26,3 \%$, passando de 38.610 matrículas em 2014 para 48.753 em 2018. Ao passo que se observarmos o percentual de alunos matriculados no AEE em relação às matrículas na classe comum, temos o seguinte: em $2014-36,8 \%, 2015$ - 39,4\%, 2016 - 39,4\%, 2017 - 45,3\% e 2018 - 46,5\%, logo, podemos dizer que o aumento de matrículas no AEE foi significativo, tendo em vista que no período esse foi crescente, sendo que mesmo entre 2015 e 2016, quando as matrículas nas classes comuns diminuíram, percentualmente as matrículas no AEE se mantiveram.

As matrículas nas instituições especializadas sem fins lucrativos parceiras das secretarias de educação estadual e municipais tiveram queda de $19 \%$ no período analisado, passando de 35.511 em 2014 para 28.837 em 2018 (Tabela 2), segundo a Portaria Interministerial $n^{\circ}$ 10/2017, no ano de 2017 para repasse do Fundeb em 2018, as matrículas da educação especial nas instituições especializadas sem fins lucrativos parceiras com o estado foram 17.942, e 10.063 matrículas são relativas às parcerias com os órgãos de educação municipais, o que corresponde a 64\% e 36\%, respectivamente (BRASIL, 2017b), isso demonstra que a grande maioria de parcerias ocorrem com a SEE-SP no estado.

Ainda na Tabela 2 podemos observar os valores estimados para repasse do Fundeb, que variam de acordo com o valor aluno/ano e o número de matrículas, assim como os percentuais relativos às matrículas nas instituições parceiras: no ano de 2014 foi de $20 \%$, em 2015 foi de $18 \%$, em 2016 de 19\%, percentual maior que do ano anterior, apesar de o número de matrículas ter caído, ele foi compensado pela também queda das matrículas nas classes comuns, em 2017 foi de $17 \%$ e em 2018 girou em torno de 16\%. Podemos observar assim uma tendência de queda dos percentuais de 2016 até 2018.

O que nos chama a atenção ao analisar a Tabela 2 é que, apesar de o estado de São Paulo registrar um número de matrículas elevado nas classes comuns e no AEE - matrículas estas de alunos que frequentam a classe comum e alunos que frequentam o AEE no contraturno, caracterizando a educação especial na perspectiva inclusiva -, as secretarias de educação ainda mantêm parcerias com um contingente significativo de instituições especializadas que oferecem educação especial substitutiva, as quais acolhem soma expressiva de matrículas, em 2018 - 28.837 matrículas. Isso culmina em valores expressivos sendo repassados por meio do Fundeb a essas instituições, em 2018 estimados em R\$ 129.919.912,84, recursos que poderiam estar sendo injetados em ações de implementação da educação especial na perspectiva inclusiva nas redes públicas de ensino.

Temos na Tabela 3 a série histórica de 2014 até 2017, em que apresentamos os valores pagos pela SEE-SP para as instituições sem fins lucrativos que oferecem educação especial 
Plano Nacional de Educação 2014 e o Plano Estadual de Educação 2016

substitutiva e as matrículas nessas instituições correspondentes ao repasse do Fundeb para as instituições parceiras de educação especial para o "Governo Estadual" (BRASIL, 2014; 2015a; 2015b; 2016; 2017b). Com essas informações, fizemos um cálculo do valor aluno/ano pago pela SEE-SP para essas instituições; e, para fazermos uma análise comparativa, trouxemos os valores do aluno/ano Fundeb da Educação Especial para o estado de São Paulo nesses anos. Devemos deixar claro que esses números apresentados podem não corresponder ao número exato de alunos atendidos nessas instituições e nem aos valores aluno/ano pagos, pois nesta pesquisa não apuramos os Termos de Colaboração firmados com cada instituição, mas somente as Portarias Interministeriais MEC/FNDE que trazem a operacionalização do Fundeb para os exercícios analisados.

Tabela 3 - SEE-SP - valores pagos para as instituições parceiras que oferecem educação especial - 2014-2017 (valores nominais em $R \$$ )

\begin{tabular}{lcccc}
\hline Ano & $\begin{array}{c}\text { Matrículas em } \\
\text { instituições que } \\
\text { oferecem educação } \\
\text { especial paceiras da } \\
\text { SEE-SP para } \\
\text { repasse Fundeb }\end{array}$ & $\begin{array}{c}\text { Valores pagos pela SEE- } \\
\text { SP às instituições } \\
\text { parceiras que oferecem } \\
\text { educação especial }\end{array}$ & $\begin{array}{c}\text { Valor aluno/ano } \\
\text { pagola SEE-SP } \\
\text { instituições } \\
\text { parceiras que } \\
\text { oferecem } \\
\text { educação especial }\end{array}$ & $\begin{array}{c}\text { Valor aluno/ano } \\
\text { Fundeb Educação } \\
\text { Especial para o estado } \\
\text { de São Paulo }\end{array}$ \\
\hline 2014 & 24.769 & $121.506 .332,55$ & $4.905,58$ & $3.640,67$ \\
\hline 2015 & 24.214 & $137.806 .809,20$ & $5.691,20$ & $4.068,60$ \\
\hline 2016 & 20.935 & $132.915 .651,20$ & $6.348,97$ & $4.273,85$ \\
\hline 2017 & 19.604 & $128.421 .100,86$ & $6.550,76$ & $4.304,32$ \\
\hline
\end{tabular}

Fonte: Organizado pelas autoras a partir de: Portarias Interministeriais MEC/FNDE (BRASIL, 2014b; 2015a; 2016a; 2016b; 2017b) (Nota 1); Balanços Consolidados - Despesas Pagas (2014-2017), disponíveis no portal da Secretaria de Fazenda do Estado de São Paulo, Balanços Consolidados - Despesas Pagas (2014-2017) (SÃO PAULO, 2017) (Nota 2).

$\mathrm{Na}$ Tabela 3, observa-se que, entre os anos de 2014 e 2017, o número de alunos atendidos nas instituições parceiras com a SEE-SP passou de 24.769 para 19.604 - o que corresponde a uma redução de aproximadamente $20,8 \%$. No que tange aos valores pagos pela SEE-SP a essas instituições, verifica-se que, embora tenham ocorrido reduções nos dois últimos anos analisados, quando comparado o valor de 2017 ( $\mathrm{R} \$ 128.421 .100,86)$ em relação ao de 2014 ( $R \$ 121.506 .332,55)$, houve um aumento em torno de $5,7 \%$. No tocante ao valor do Fundeb, ocorreram consecutivos acréscimos, sendo 18,2\% o registrado entre 2014 e 2017.

Quando observamos os valores pagos - que calculamos por aluno/ano -, houve um aumento de $33,5 \%$ no período, ou seja, percentualmente superior ao aumento dos valores pagos, pois nesse período houve uma diminuição no número de matrículas, mas não nos pagamentos. Se compararmos os valores calculados por aluno/ano pagos pela SEE-SP e os valores aluno/ano da educação especial do Fundeb para o estado, constatamos que todos são maiores, e percentualmente as diferenças para maior são de 34,7\% (2014), 40\% (2015), $48,5 \%$ (2016) e 52,2\% (2017), observe-se que as diferenças aumentaram substancialmente. Com esses valores apresentados, podemos afirmar que nas parcerias firmadas pela SEE-SP com as instituições os valores pagos são muito superiores aos valores do Fundeb para a educação especial.

No ano de 2018, a previsão era de que no estado de São Paulo fossem repassados valores do Fundeb para 321 instituições que ofereciam educação especial, sendo que 267 
Plano Nacional de Educação 2014 e o Plano Estadual de Educação 2016

delas eram Apaes (BRASIL, 2018a). Do total de instituições, 162 mantinham parcerias com a SEE-SP e com secretarias municipais de educação, concomitantemente, 126 mantinham parceria somente com a SEE-SP e 33 delas mantinham parceria apenas com as secretarias municipais de educação (BRASIL, 2018a), perfazendo um total de 28.837 alunos matriculados nessas instituições (BRASIL, 2018b). Devemos observar que para o repasse dos valores do Fundeb para essas instituições conveniadas "[...] são consideradas as matrículas apuradas no Censo Escolar mais atualizado [...]" (BRASIL, 2017a), ou seja, para o repasse de 2018 foram consideradas as matrículas de 2017. No final do ano, o Ministério da Educação e o Ministério da Fazenda em Portaria Interministerial divulgam a operacionalização do Fundeb, com os dados estimados de matrículas por municípios e estados e, no ano seguinte, quando o Inep publica os dados das Sinopses Estatísticas da Educação Básica oficiais, uma nova Portaria é publicada com as retificações necessárias. Ressaltamos que nesses demonstrativos do FNDE, de repasses do Fundeb para as instituições conveniadas, não conseguimos desagregar as matrículas entre parcerias estaduais e municipais quando as instituições mantêm parcerias com órgãos dos dois entes federados concomitantemente - as matrículas são desagregadas somente por etapas e modalidades de ensino.

Observa-se que, quando comparamos os dados da Tabela 2 com os dados da Tabela 3 , relacionados aos valores pagos às instituições parceiras, os da Tabela 3 deveriam ser sempre menores, haja vista que na Tabela 2 os valores correspondem às parcerias com a SEE-SP e com as secretarias municipais, por não conseguirmos desagregar esses dados de matrículas nos documentos do FNDE. Ocorre o mesmo com os números de alunos atendidos nessas instituições. As diferenças entre os valores pagos pela SEE-SP e os valores estimados para os repasses do Fundeb devem corresponder às matrículas das parcerias com as secretarias municipais; essas diferenças variaram de ano para a ano no período apresentado, sendo que somente em 2014 temos valor maior na estimativa de repasse do Fundeb - R\$ $7.777 .499,82$, nos outros três anos os valores pagos pela SEE-SP são maiores que o das estimativas de repasses do Fundeb: em 2015 - R $\$ 6.618 .870,80$, em 2016 - R $\$ 1.375 .095,90$ e em 2017 - R\$ 4.017.644,22. Interessante salientar que os valores que estimamos na Tabela 2 para o repasse do Fundeb são relativos às parcerias com a SEE-SP e com as secretarias municipais também. Logo, podemos concluir, reiterando afirmações anteriores, que a SEESP financia, por meio de parcerias, as instituições de educação especial no estado com valores superiores aos estimados e repassados pelo Fundeb para o mesmo fim.

Com os dados apresentados nas tabelas, procuramos retratar um panorama numérico da educação especial no estado de São Paulo, por meio do quantitativo de matrículas dos alunos da educação especial, dos valores aluno/ano do Fundeb para esses alunos, e dos valores estimados dos repasses do Fundeb para as instituições parceiras da SEE-SP que oferecem educação especial substitutiva.

Devemos registrar as dificuldades encontradas para a obtenção de dados de financiamento da educação especial e, no caso mais específico, das matrículas nas instituições parceiras com as secretarias do estado e municipais de São Paulo. Não há a desagregação desses dados e valores nos documentos que utilizamos, exemplo claro é que não conseguimos separar o número de matrículas com o município e/ou com o estado quando as instituições mantêm parcerias com os dois, mesmo recorrendo às informações disponibilizadas no portal da UFPR, que faz uso dos microdados do Censo Escolar. Outro 
Plano Nacional de Educação 2014 e o Plano Estadual de Educação 2016

exemplo são as matrículas no AEE, que nas Sinopses Estatísticas da Educação Básica do Inep só aparecem como turmas e estabelecimentos e não como número de matrículas, o que dificulta a identificação dessas por etapa de ensino, por dependência administrativa, por categoria de deficiência. Temos intenções de dar continuidade a esse estudo fazendo uso de outras fontes de dados, que poderão dar-nos maior precisão e assim conseguirmos atingir os objetivos com mais facilidade, sabendo-se da importância de pesquisarmos o financiamento da educação especial como balizador de políticas de educação especial.

\section{Algumas Considerações Conclusivas}

A partir da Política Nacional de Educação Especial na Perspectiva da Educação Inclusiva (BRASIL, 2008), conforme apresentado, as matrículas do alunado elegível ao atendimento pela educação especial foram ampliadas nas classes comuns. Consequentemente, é esperado que estados e municípios tenham feito alterações em suas redes de ensino para incluir esses alunos. Esse direcionamento preferencial de matrícula foi reforçado na Meta 4 do PNE-2014, destinada à educação especial.

Todavia, segundo Borowsky (2013), é fato recorrente que documentos com diretrizes da educação básica, quando tratam da educação especial, sempre fazem referência às instituições privadas sem fins lucrativos. Nesse sentido, verificamos que tanto o PNE-2014, assim como o Decreto $n^{\circ}$. 6.278/2007 (BRASIL, 2007), garantem o repasse de verbas provenientes do Fundeb a instituições de educação especial parceiras com o poder público. Desse modo, os sistemas de ensino reorganizaram as parcerias com as instituições sem fins lucrativos que oferecem educação especial, fazendo assim a manutenção histórica da delegação desses serviços à esfera privada, por sua vez, essas instituições tiveram que ajustar suas formas de atendimento para se adequarem às exigências dos contratos de convênio/parceria técnico e financeiro com as secretarias de educação (PERONI, 2016; SOUZA, 2017; 2018).

De maneira específica, no estado de São Paulo, como apresentado, temos 321 instituições sem fins lucrativos parceiras da SEE-SP e de secretarias municipais, conforme demonstrativo de repasse do Fundeb de 2018, sendo que 288 instituições das 321 mantiveram parceria com a SEE-SP, e algumas destas mantêm concomitantemente parcerias também com as secretarias de educação municipais, apoiadas pelo PEE-SP-2016, o qual corrobora o texto do PNE-2014, assim como pela legislação estadual específica que garante o repasse do Fundeb a essas instituições por meio das parcerias, em forma de Termos de Colaboração Técnica e Financeira. Nessa realidade, somente para exemplificar, temos 29.902 alunos frequentando a educação básica substitutiva no ano de 2017 , em instituições sem fins lucrativos com parcerias estadual e/ou municipal, sendo que 19.604 alunos frequentavam as instituições especializadas sem fins lucrativos parceiras da SEE-SP (BRASIL, 2016) e foram pagos para essas instituições o valor de $R \$ 128.421 .100,86$ (cento e vinte e oito milhões, quatrocentos e vinte um mil, cem reais e oitenta e seis centavos), correspondentes a essas matrículas, ou seja, um valor aluno/ano estimado em $\mathrm{R} \$ 6.550,76$ (seis mil, quinhentos e cinquenta e dois reais e setenta e seis centavos), valor superior $52,2 \%$ em relação ao valor aluno/ano do Fundeb para a educação especial no estado.

Em termos financeiros, tais parcerias da SEE-SP representam valores elevados $e$ significativos para a subsistência dessas instituições, o que é corroborado por Laplane, 
Plano Nacional de Educação 2014 e o Plano Estadual de Educação 2016

Caiado e Kassar (2016, p. 42), que apontam: "Se a presença do setor privado é reconhecida pelo poder público como uma colaboração importante para a efetivação de formas diferenciadas de atendimento, para o setor privado, a busca por recursos públicos é fundamental para sua existência".

Logo, o grande número de parcerias apoia o funcionamento de instituições que oferecem ensino especializado substitutivo ao ensino nas classes comuns públicas e privadas, o que nos remete às políticas que a SEE-SP adota em relação à educação especial e ao alunado elegível ao atendimento pela educação especial, política esta que não adere plenamente à perspectiva inclusiva. Ademais, grande parte desses recursos financeiros poderiam ser utilizados em ações de implementação da educação especial na perspectiva inclusiva nas redes públicas de ensino.

\section{Referências}

BOROWSKY, F. A relação entre a educação pública e privada na educação especial brasileira. In: PERONI, V. M. V. Redefinições das fronteiras entre o público e o privado: implicações para a democratização da educação. Brasília: Liber Livro, 2013.

BRASIL. Congresso Nacional. Constituição da República do Brasil de 1988. Diário Oficial da União, Brasília, 1988. Disponível em: <https://bit.ly/2H0SpiU>. Acesso em: 18 nov. 2017.

BRASIL. Casa Civil. Lei 9.394, de 20 de dezembro de 1996. Estabelece as diretrizes e bases da educação nacional. Diário Oficial da União, Brasília, 1996a. Disponível em: <https://bit.ly/2fWX88v>. Acesso em: 04 dez. 2017.

BRASIL. Presidência da República. Decreto 6.278, de 29 de novembro de 2007. Altera o Decreto no 6.253, de 13 de novembro de 2007, que dispõe sobre o Fundo de Manutenção e Desenvolvimento da Educação Básica e de Valorização dos Profissionais da Educação FUNDEB e regulamenta a Lei no 11.494, de 20 de junho de 2007. Diário Oficial da União, Brasília, 2007a. Disponível em: <https://bit.ly/2Q4kmdG>. Acesso em: 12 out. 2017.

BRASIL. Ministério da Educação. Secretaria de Educação Especial. Política Nacional de Educação Especial na Perspectiva da Educação Inclusiva. 2008. Disponível em: <https://bit.ly/20BktZT>. Acesso em: 20 jul. 2017.

BRASIL. Casa civil. Lei 13.005, de 25 de junho de 2014. Aprova o Plano Nacional de Educação - PNE e dá outras providências. Diário Oficial da União, Brasília, 2014a. Disponível em: <https://bit.ly/1LbcL4B>. Acesso em: 10 jan. 2017.

BRASIL. Ministério da Educação. Fundo Nacional de Desenvolvimento da Educação. Portaria Interministerial $n^{0} 15$, de 25 de novembro de 2014. Divulga os parâmetros de operacionalização do Fundeb para o exercício de 2014. Brasília, 2014b. Disponível em: <https://bit.ly/2S34tFm>. Acesso em: 15 dez. 2017.

BRASIL. Casa Civil. Lei 13.204, de 14 de dezembro de 2015. Altera a Lei no 13.019, de 31 de julho de 2014, que estabelece o regime jurídico das parcerias voluntárias, envolvendo ou não transferências de recursos financeiros, entre a administração pública e as organizações da sociedade civil, em regime de mútua cooperação, para a consecução de finalidades de interesse público; define diretrizes para a política de fomento e de colaboração com organizações da sociedade civil; institui o termo de colaboração e o termo de fomento. Diário 
Plano Nacional de Educação 2014 e o Plano Estadual de Educação 2016

Oficial da União, Brasília, 2015a. Disponível em: <https://bit.ly/2A5VtnG>. Acesso em: 13 dez. 2017.

BRASIL. Ministério da Educação. Fundo Nacional de Desenvolvimento da Educação. Portaria Interministerial $\mathbf{n}^{\circ} \mathbf{8}$, de 5 de novembro de 2015. Retifica e divulga os parâmetros anuais de operacionalização do Fundeb para o exercício de 2015. Brasília, 2015b. Disponível em: <https://bit.ly/2sLQFAQ>. Acesso em: 15 dez. 2017.

BRASIL. Ministério da Educação. Fundo Nacional de Desenvolvimento da Educação. Portaria Interministerial $n^{\circ}$ 6, de 21 de julho de 2016. Divulga os parâmetros de operacionalização do Fundeb para o exercício de 2016. 2016a. Disponível em: <https://bit.ly/2TvBk3f>. Acesso em: 15 dez. 2017.

BRASIL. Ministério da Educação. Resolução $n^{\circ}-1$, de 28 de julho de 2016. Aprova as ponderações aplicáveis entre diferentes etapas, modalidades e tipos de ensino da educação básica, para vigência no exercício de 2017. 2016b. Diário Oficial da União, Brasília, sessão 1, n. 145. p. 18.

BRASIL. Ministério da Educação. Instituto Nacional de Estudos e Pesquisas Educacionais Anísio Teixeira. Orientações de preenchimento do censo escolar de 2017. 2017a. Disponível em: <https://bit.ly/2RY7frF>. Acesso em: 15 nov. 2017.

BRASIL. Ministério da Educação. Fundo Nacional de Desenvolvimento da Educação. Portaria Interministerial $\mathbf{n}^{\circ} \mathbf{1 0}$, de 28 de dezembro de 2017. Estabelece os parâmetros operacionais para o FUNDEB, no exercício de 2018. Brasília, 2017b. Disponível em: <https://bit.ly/2NPeuQv>. Acesso em: 15 ago. 2018.

BRASIL. Ministério da Educação. Fundo Nacional de Desenvolvimento da Educação. Instituições conveniadas e alunos considerados na distribuição de recursos do Fundeb - 2018. Brasília, 2018a. Disponível em: <https://bit.ly/2S9vd6S>. Acesso em: 15 ago. 2018.

BUENO, J. G. S. Educação Especial brasileira: integração/segregação do aluno diferente. São Paulo: Educ, 1993.

DI PIETRO, M. S. Z. Parcerias na Administração Pública. 11. ed. Rio de Janeiro: Forense, 2017.

FERREIRA, J. R. A exclusão da diferença: A educação do portador de deficiência. Piracicaba: Unimep, 1993.

JANNUZZI, G. A luta pela educação do deficiente mental no Brasil. Campinas: Editora Autores Associados, 1992.

KASSAR, M. C. M. Liberalismo, neoliberalismo e educação especial: algumas implicações. Caderno CEDES, Campinas, v. 19, n. 46, set. 1998.

LAPLANE, A. L. F.; CAIADO, K. R. M.; KASSAR, M. C. M. As relações público-privado na educação especial: tendências atuais no Brasil. Revista Teias (UERJ Online), Rio de Janeiro, v. 17, p. $40-55,2016$.

MAZZOTTA, M. J. S. Educação Especial no Brasil: História e políticas públicas. São Paulo: Cortez Editora, 2003. 
Plano Nacional de Educação 2014 e o Plano Estadual de Educação 2016

MELETTI, S. M. F.; RIBEIRO, K. Indicadores educacionais sobre a educação especial no Brasil. Caderno Cedes, Campinas, v. 34, n. 93, p. 175-189, maio-ago. 2014. Disponível em: <https://bit.ly/2E2ONKj>. Acesso em: 23 ago. 2018.

MELO, D. C. F. de; SILVA, J. H. da. A educação especial no PNE 2014-2024: intencionalidades, contradições e desafios. In: REUNIÃO REGIONAL SUDESTE ANPED, 13., 2018, Campinas. Anais... Campinas: Anped, 2018.

MENDES, E. G. A radicalização do debate sobre inclusão escolar no Brasil. Revista Brasileira de Educação, Rio de Janeiro, v. 11, n. 33, set./dez. 2006.

PERONI, V. M. V. Relação público-privado na educação básica: a democratização da educação? Movimento Revista de Educação, Niterói, v. 5, p. 1-27, 2016.

REBELO, A. S. O atendimento educacional especializado no Brasil (2003-2014). Revista Educação Online, n. 20, p. 62-78, set-dez. 2015.

SÃO PAULO (Estado). Assembleia Legislativa do Estado de São Paulo. Lei no 16.279, de 08 de julho de 2016. Diário Oficial do Estado de São Paulo, São Paulo, 2016a. Disponível em: <https://bit.ly/2PDxSWb>. Acesso em 14 nov. 2017.

SÃO PAULO (Estado). Conselho Estadual de Educação. Resolução SE 59, de 22-11-2016. São Paulo, 2016b. Disponível em: <https://bit.ly/2DsxeUa>. Acesso em: 22 out. 2017.

SÃO PAULO (Estado). Governador do Estado. Decreto n 62.294, de 06 de dezembro de 2016. Diário Oficial do Estado de São Paulo, São Paulo, 2016c. Disponível em: <https://bit.ly/2A4D2A1>. Acesso em: 22 out. 2017.

SÁ-SILVA, J. R.; ALMEIDA, C. D.; GUINDANI, J. F. Pesquisa documental: pistas teóricas e metodológicas. Revista Brasileira de História \& Ciências Sociais, Rio Grande, n. 1, jul. 2009.

SOUZA, M. M. Produto n 01: Documento técnico contendo diagnóstico sobre o atendimento especializado desenvolvido pelas escolas, centros especializados, instituições públicas e privadas, universo de estudantes e professores, nas regiões sul e centro-oeste. Brasília: MEC/Secadi/DPEE/UNESCO. 2017. Mimeo.

SOUZA, M. M. Sistemas estaduais de ensino na região Sul: arranjos para o oferecimento de educação especial e parcerias público-privadas entre os Estados e escolas especializadas. In: RANIERI, N. B.; ALVES, A. L. Direito à educação e direitos na educação: em perspectiva interdisciplinar. São Paulo: Cátedra Unesco de Direito à Educação; Universidade de São Paulo (USP), 2018.

SOUZA, M. M.; PAGAIME, A.; ROSA, M. R. Da educação infantil ao ensino superior: as matrículas garantem a perspectiva inclusiva na educação? In: CONGRESSO BRASILEIRO DE EDUCAÇÃO ESPECIAL, 8., 2018, São Carlos. Anais... São Carlos: ABPEE, 2018. 
Plano Nacional de Educação 2014 e o Plano Estadual de Educação 2016

Marcia Maurilio Souza possui graduação em Serviço Social pela Universidade São Francisco (1985) e mestrado em Educação pela Universidade de São Paulo (2010). Atualmente é Doutoranda na Faculdade de Educação da Universidade de São Paulo, Avaliadora de Cursos do Ensino Superior pelo Inep, Professora da Universidade Estácio de Sá, da Universidade Municipal de São Caetano do Sul e Pesquisadora voluntária da Universidade de São Paulo. ORCID: http://orcid.org/0000-0002-3975-7209

E-mail: marcia.maurilio@usp.br

Vanessa Dias Bueno de Castro é doutora em Educação, pelo programa de Pós-Graduação em Educação da Universidade de São Paulo - USP. Mestra em Educação Escolar pelo programa de Pós-Graduação em Educação Escolar da Faculdade de Ciências e Letras da Unesp Campus Araraquara em 2015. Graduada em Ciências Sociais (Bacharelado e Licenciatura) pela Universidade Estadual Paulista 'Júlio de Mesquita Filho' - UNESP Campus Araraquara em 2011.

ORCID: http://orcid.org/0000-0003-1433-3669

E-mail: van.bcastro@gmail.com

Rosângela Gavioli Prieto é graduada em Pedagogia, com habilitações em Educação do Deficiente pela Pontifícia Universidade Católica de Campinas (1981) e em Administração Escolar pela Universidade de Guarulhos (1987); graduada em Psicologia pela Universidade de Guarulhos (1994); mestre em Educação Especial (Educação do indivíduo especial) pela Universidade Federal de São Carlos (1990); doutora em Educação pela Universidade de São Paulo (2000). Atualmente, é professora da Faculdade de Educação da Universidade de São Paulo.

ORCID: http://orcid.org/0000-0003-4013-1163

E-mail: rosangel@usp.br 


\section{Editores do volume 10}

Márcia Aparecida Jacomini - Universidade Federal de São Paulo, Brasil

José Marcelino de Rezende Pinto - Universidade de São Paulo, Brasil

\section{Comitê Editorial}

Nalú Farenzena - Universidade Federal do Rio Grande do Sul, Brasil

Juca Gil - Universidade Federal do Rio Grande do Sul, Brasil

Theresa Adrião - Universidade Estadual de Campinas, Brasil

Ângelo Ricardo de Souza - Universidade Federal do Paraná, Brasil

\section{Conselho Editorial}

\section{Alejandro Morduchowicz}

Universidad Pedagógica, Provincia de Buenos Aires, Argentina

Andréa Barbosa Gouveia

Universidade Federal do Paraná, Brasil

Fernanda Saforcada

Universidade de Buenos Aires, Argentina

Jacques Velloso

Universidade de Brasília, Brasil

João Monlevade

Senado Federal, Brasil

Jorge Abrahão de Castro

Instituto de Pesquisa Econômica Aplicada / IPEA, Brasil

Lisete Regina Gomes Arelaro

Universidade de São Paulo, Brasil

Luis Carlos Sales

Universidade Federal do Piauí, Brasil

Luiz de Sousa Junior

Universidade Federal da Paraíba, Brasil

Luiz Fernandes Dourado

Universidade Federal de Goiás, Brasil

Magna França

Universidade Federal do Rio Grande do Norte, Brasil

Marcos Edgar Bassi

Universidade Federal de Santa Catarina, Brasil

Maria Angélica Pedra Minhoto

Universidade Federal de São Paulo, Brasil

Maria Beatriz Luce

Universidade Federal do Rio Grande do Sul, Brasil

Maria Dilnéia Espíndola Fernandes

Universidade Federal de Mato Grosso do Sul, Brasil

Nelson Cardoso do Amaral

Universidade Federal de Goiás, Brasil

Nicholas Davies

Universidade Federal Fluminense, Brasil

Robert E. Verhine

Universidade Federal da Bahia, Brasil

Romualdo Portela de Oliveira

Universidade de São Paulo, Brasil

Rosana Gemaque Rolim

Universidade Federal do Pará, Brasil

Rubens Barbosa de Camargo

Universidade de São Paulo, Brasil

Theresa Adrião

Universidade Estadual de Campinas, Brasil

Tristan McCowan

University of London, Reino Unido

Vera Jacob

Universidade Federal do Pará, Brasil

Vera Peroni

Universidade Federal do Rio Grande do Sul, Brasil

Vitor Henrique Paro

Universidade de São Paulo, Brasil

\section{Equipe editorial}

Apoio ao Comitê Editorial: Caio Cabral da Silva

Diagramação, Revisão de português e normalização: Edson Leonel de Oliveira

Revisão de inglês: Sabrina Ferreira

Fineduca - Revista de Financiamento da Educação

Associação Nacional de Pesquisa em

Financiamento da Educação

e-mail: revista.fineduca@gmail.com | site: http://seer.ufrgs.br/fineduca 